\title{
Method for Accounting for Macroscopic Heterogeneities in Reactor Material Balance Generation in Fuel Cycle Simulations
}

\section{Abstract}

This paper describes the addition of spatially dependent power sharing to a methodology used for calculating the input and output isotopics and burnup of nuclear reactors within a nuclear fuel cycle simulator. Neutron balance and depletion calculations are carried out using pre-calculated fluencebased libraries. These libraries track the transmutation and neutron economy evolution of unit masses of nuclides available in input fuel. The work presented in the paper generalizes the method to simulate reactors that contain more than one type of fuel as well as strong spatial and flux heterogeneities, for instance breeders with a driver-blanket configuration. To achieve this, spatial flux calculations are used to determine the fluence-dependent relative average fluxes inside macroscopic spatial regions. These fluxes are then used to determine the average power of macroscopic spatial regions as well as to more accurately calculate region-specific transmutation rates. The paper presents several cases where the fluence based approach alone would not have been sufficient to determine results. 


\section{Introduction}

The fluence based neutron balance method, used by the nuclear reactor simulator Bright-lite [1], calculates input and output compositions of fuel in nuclear fuel cycle simulators. The method be used to calculate the blending ratio of multiple streams of arbitrary isotopic composition in order to obtain input fuel compositions that meet specified burnup, fluence, or conversion ratio objectives.

Bright-lite operates by characterizing the evolution of the neutron balance for each nuclide present in the fuel on the basis of fluence. The method uses low-order approximations to account for the effects of micro heterogeneities in the fuel lattice on the neutron balance, for instance flux differences between fuel and coolant regions. Effects of larger heterogeneities in the core, such as variations between batches having resided in the core for different lengths of time, are calculated by assuming that each macroscopic region is maintained at equal fission power density. This equal power sharing assumption was shown to lead to adequate results for a range of reactors and is accurate in an approximate sense as fuel managers strive to adjust core loadings so that power is distributed as uniformly as possible.

The methodology defined in this paper uses macro-region based coupled spatial flux and burnup calculations to enable the fluence based approach to treat strongly heterogeneous cores and fuel loadings. Homogeneous regions are defined within the reactor core at both the micro (fuel-cladding regions) and macro (batches) levels. Each region has a unique, time-dependent relative flux, which is used to advance the fluence of the material(s) within that region.

Eliminating the equal power sharing assumption enables potentially better treatment of batch-level homogeneous cores and grants a fuel cycle simulator the ability to dynamically model heterogeneous cores with reloads whose input and output isotopics evolve over time. For example, a homogeneous core cannot be used to model a breeder reactor due to no-power or low-power producing regions such as breeding blankets. In addition, the heterogeneous approach will allow irradiation targets, for instance americium-loaded transmutation pins, to be modeled. The new method will also improve results for mixed fuel types (such as uranium and plutonium in light water reactors) which had previously been treated as spatially decoupled. It is important to note that this method still requires its users to generate cross sections which are appropriate to the neutron spectra within the fuels or targets.

The next section will review methods used by nuclear fuel cycle (NFC) simulators to account for evolving input isotopics when determining input fuel composition and output burnup and composition. Subsequently, the elementary diffusion-theory based methodology which replaces the zero-dimensional relative flux calculation of Bright-lite is described. Results using the new methodology are presented next, followed by conclusions. 


\section{Input Composition Calculations}

NFC simulators have a method for specifying the output composition and burnup if the composition of the input fuel is specified. This section reviews two methods to determine an input composition when multiple material streams are available to be blended. The accuracy of these methods is dependent on the number of nuclides tracked as well as the available one- or multi-group cross section data. Their general goal is to determine the input fuel composition that meets user- or fuel cycle simulator-defined output composition, reactivity, or burnup targets.

\section{THE REACTIVITY WORTH APPROACH}

This method, which was proposed for implementation in VISION [2], is used to match the reactivity of the available (usually recycled) fuel to that of a reference fuel composition specified for the reactor. The available fuel streams are mixed so that the reactivity of the fresh resultant mixture represents a minimized change from the reference.

In order to determine the reactivity of the available fuel, first every nuclide in its composition is categorized according to the blending stream to which it belongs. For instance, if a uranium and a transuranic stream are being blended, nuclides of the $U$ and TRU type are considered. Next, these nuclides' fractions in the reference fuel mixture are determined within their category and used with available cross section data to calculate the terms in the six-factor formula. A reactivity worth is then calculated for each nuclide. The reactivity worths are used to adjust the mass ratio of the streams being blended, leading to the fresh fuel that provides the best initial reactivity match to the reference. This method does not directly consider differences in the evolution of the multiplication factor with burnup as the isotopic content of the fuel is changed, so it would likely be most appropriate if the perturbations from the reference cases remain small. Due to this limitation, the Bright-lite methodology does not base its calculations on initial reactivity.

\section{THE D-FACTOR METHOD}

This method, which has been utilized by COSI [3], focuses on the net neutron contribution of each initial nuclide present in the fuel as it transmutes into fission products. First, the neutron consumption per fission of each nuclide $i\left(D_{i}\right)$ is defined as the net "number of neutrons needed to transform the nucleus and its reaction products into fission products" [4]. Therefore a positive $D$ corresponds to a net neutron consumption by the species and its descendants, and a negative $D$ to production of neutrons. The D-factor captures the characteristics of each reactor via cross sections which depend on the flux spectrum of the reactor and the burnup and residence time of fuel. The relative fraction of each nuclide $\left(m_{i}\right)$ in fresh fuel is used to find the D-factor for the fuel $\left(D_{F U E L}\right)$ using equation (4).

$$
\mathrm{D}_{\mathrm{FUEL}}=\sum \mathrm{D}_{\mathrm{i}} \mathrm{m}_{\mathrm{i}}
$$

Then, equation (5) is used to determine core neutron balance. 


$$
\mathrm{G}=\mathrm{S}_{\mathrm{ext}}-\mathrm{D}_{\mathrm{FUEL}}-\text { losses }
$$

Where $S_{\text {ext }}$ is a potential external neutron source and losses is the neutron losses (by leakage) per fission in the reactor. When $G$, the neutron surplus, is positive, the core is assumed to maintain criticality during burnup. The objective of the methodology is to create valid input fuel compositions for use in COSI by blending available fuel sources to obtain $\mathrm{G}=0$. 


\section{Methodology}

The fluence based neutron balance method used in Bright-lite can simulate multiple batches with unique burnup histories by tracking key fluence-dependent properties of each batch. The method precalculates and parameterizes reactor type-specific burnup and transmutation libraries using one energy group cross sections for every nuclide which can be present in fresh fuel. The cross sections are precomputed via coupled transport-burnup calculations using representative fuel configurations, compositions, and discharge burnups. Libraries are generated using an existing depletion calculation tool (such as ORIGEN [5]) for a unit mass of the nuclide using a characteristic flux for the fuel and reactor type. Each library contains a fluence-dependent neutron production rate, neutron destruction rate, burnup, and transmutation matrix for the nuclide.

Figure 1 shows two example libraries for a representative light water reactor. Both plots illustrate the evolution of the contribution of an initial unit mass of a fuel isotope to the neutron balance. All transmutation and decay daughters of the initial masses are tracked, so their contributions are also reflected in the figures. The left follows an initial unit mass of U-235 where the neutron production rate remains greater than the destruction rate until the fluence becomes quite large and most of the U-235 atoms initially present have become fission or transmutation daughters. On the other hand, in the right figure for $\mathrm{U}-238$, the neutron destruction rate exceeds the production rate for all fluences, although both increase with fluence due primarily to the buildup of Pu-239. During runtime these isotope libraries are combined for each macroscopic spatial region on a mass-weighted basis to generate a characteristic library of the desired fuel composition.
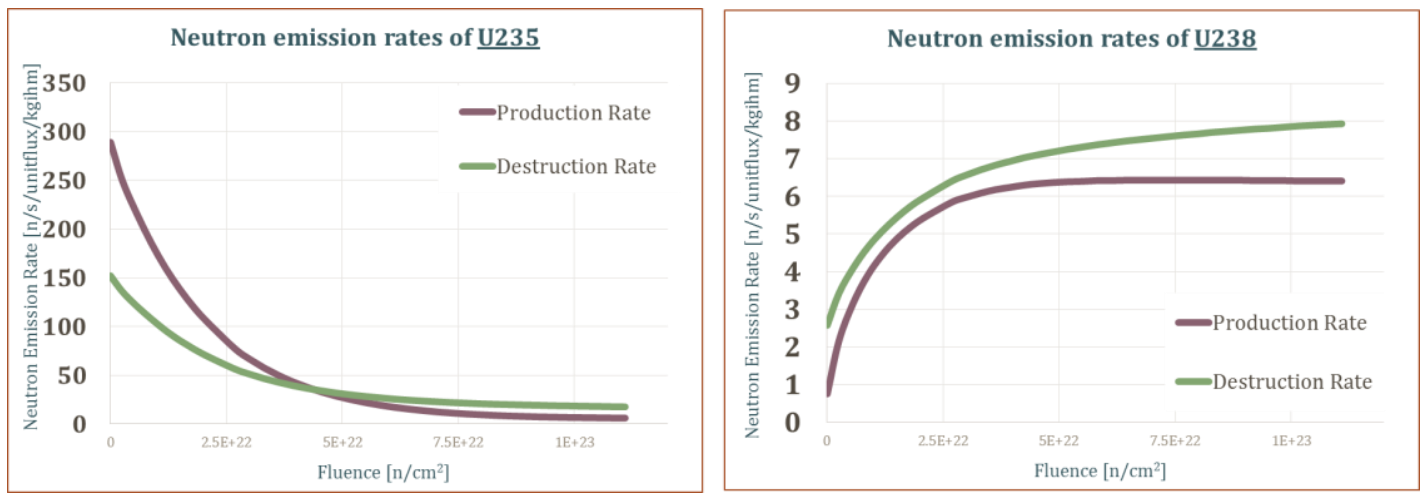

Figure 1 - Neutron production and destruction rates of U-235 and U-238 for a typical LWR.

The methodology for discharge fluence calculation can be demonstrated using an example 3-batch reactor operating in steady state with known fuel compositions. Figure 2 depicts the increase in batch fluences marching forward in time within one reactor cycle. Initially the first batch has zero fluence $\left(F^{(1)}(t=0)=0\right)$, and the third batch has the highest. 


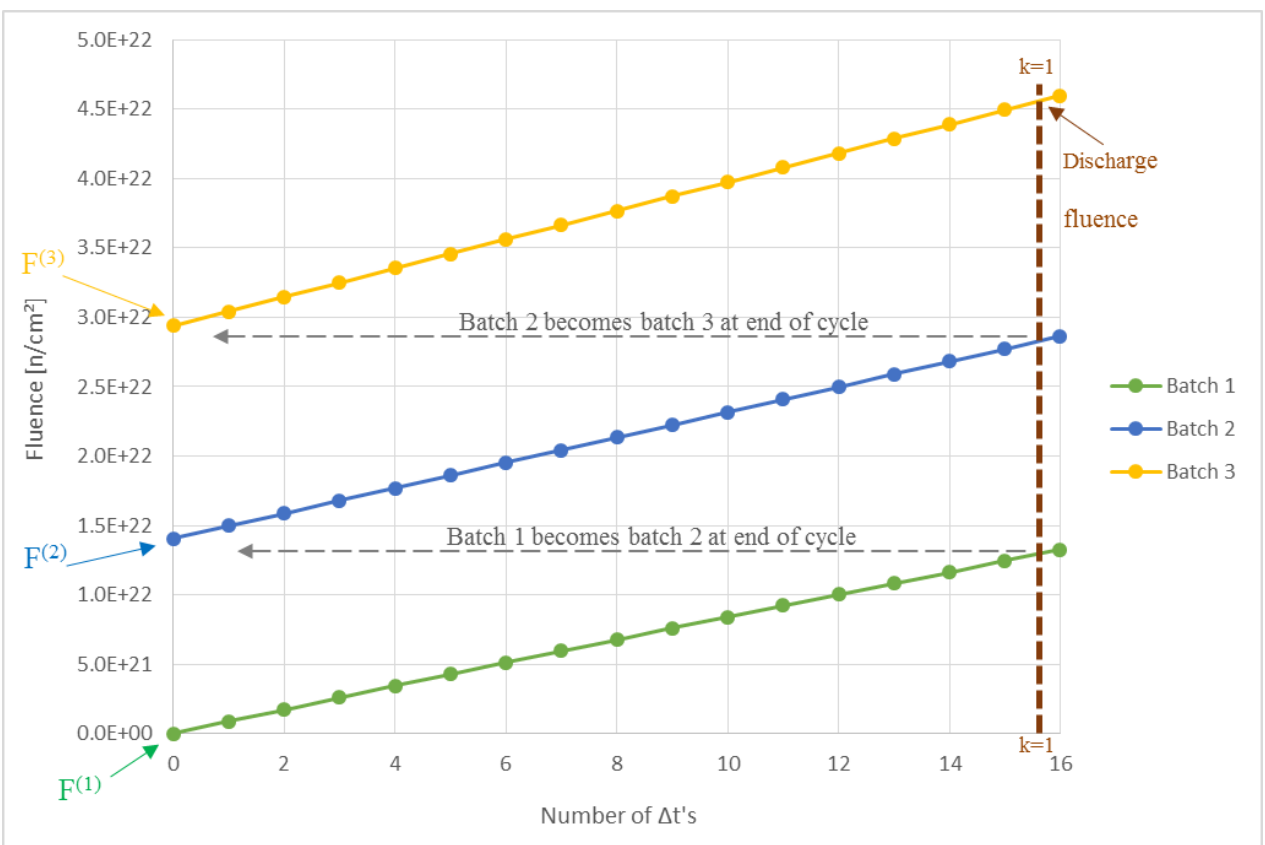

Figure 2 - Discharge fluence determination for an example 3-batch LWR

To march forward through the cycle, a time step $\Delta t$ (during which the magnitudes of the average fluxes in the region occupied by each batch are assumed constant) is implemented to calculate $\Delta \mathrm{F}^{(\mathrm{n})}(\mathrm{t})$ for each batch. In general, if the volume and time averaged flux $\left(\Phi^{(n)}(t)\right)$ in the fuel region of batch $n$ over time step starting at $t$ is known, the fluence increment $\Delta F^{(n)}(t)$ can be calculated for each batch:

$$
\Delta \mathrm{F}^{(\mathrm{n})}(\mathrm{t})\left[\frac{\mathrm{n}}{\mathrm{cm}^{2}}\right]=\Delta \mathrm{t}[\mathrm{s}] \cdot \Phi^{(\mathrm{n})}(\mathrm{t})\left[\frac{\mathrm{n}}{\mathrm{cm}^{2}} \cdot \mathrm{s}\right]
$$

The eigenvalue is calculated using the neutron production rates $\left(P^{(n)}(t)\right)$, neutron destruction rates $\left(D^{(n)}(t)\right)$, time averaged fluxes $\left(\Phi^{(n)}(t)\right)$ and the nonleakage probability $\left(P_{N L}\right)$ as given below, where there are $N$ batches.

$$
\mathrm{k}(\mathrm{t}+\Delta \mathrm{t})=\mathrm{P}_{\mathrm{NL}} \cdot \frac{\sum_{\mathrm{n}=1}^{\mathrm{N}} \mathrm{P}^{(\mathrm{n})}(\mathrm{t}+\Delta \mathrm{t}) \cdot \Phi^{(\mathrm{n})}(\mathrm{t}+\Delta \mathrm{t})}{\sum_{\mathrm{n}=1}^{\mathrm{N}} \mathrm{D}^{(\mathrm{n})}(\mathrm{t}+\Delta \mathrm{t}) \cdot \Phi^{(\mathrm{n})}(\mathrm{t}+\Delta \mathrm{t})}
$$

Reactivity is used as the discharge condition by ending the cycle and refueling when the k-value drops below unity (or unity plus a small additive factor if desired). After each time the fluence is incremented, the multiplication factor will be checked, and the process will be repeated until it is less than unity. This check is generally carried out in the absence of control absorbers (although burnable poisons can be included if present) as its objective is to determine the neutron balance if all removable control absorbers were taken out.

Once the discharge fluence of the Nth batch, $F^{(N)}$, is found, its discharge burnup and composition are obtained directly from the batch's fluence-dependent fuel library. Time is reset and the updated fluences of the other batches $\left(F^{(1)}, F^{(2)}, \ldots, F^{(N-1)}\right)$ carry to the next cycle with their indices increased by one. 
In the original implementation of Bright-lite, the spatial extent of the macroscopic regions is not specified as a point reactor approach is taken to express the global neutron balance. Refueling batches could still be thought of as occupying hypothetical macro regions, but the average fluxes for each batch were selected by matching the power density within each batch.

Without considering spatial neutron transport, the method can only determine the relative neutron flux within each batch if an assumption such as the aforementioned equal inter-batch power sharing among batches is made. But there are cases where the equal power sharing approximation would not be appropriate. Examples include driver-blanket and driver-target configurations where the power densities of the blanket or target regions are very different from that of the driver.

The methods presented in this paper overcome this limitation by making simple approximations regarding the distribution and spatial extent of the macroscopic regions. Spatial flux calculations are used to determine the relative average flux inside macroscopic spatial regions. These fluxes are then used to scale the batch- or region-specific rate of increase of fluence. The remainder of this development will consider an $\mathrm{N}$-batch driver fuel loading with an additional macroscopic region which may contain a blanket or targets. The approach generalizes to any number of concentric regions.

First, the batches are arranged in concentric cylinders as shown in Figure 3. The arrangement of the batches can vary depending on the problem. In a breeding reactor the breeding blanket could be located at the outermost shell to maximize neutron utilization. In any reactor the outermost shell can be set as a moderator/reflector region.

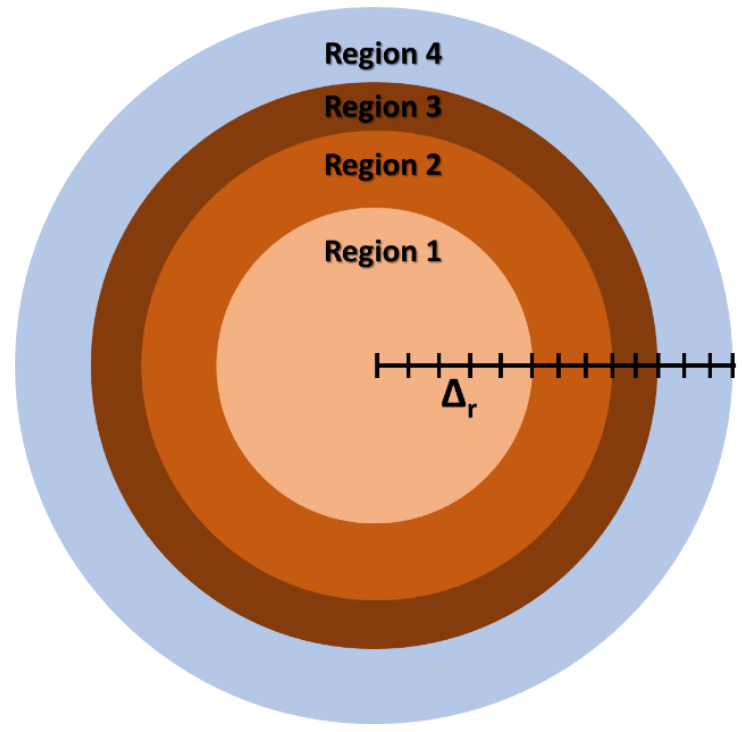

Figure 3 - Spatial batch arrangement for flux calculation.

Spatial flux calculations are repeated for every time-step in the discharge fluence determination since the change in fluence affects the material cross-sections used in this calculation. The results of the 
spatial flux calculation are used to find a unitless relative flux vector, $r^{(n)}$. Here $n$ is the region index from 1 to $N$, where $N$ is the total number of radial regions.

The relative flux distribution in the multiplying medium is determined by solving the one energy group neutron diffusion equation using concentric cylinders (infinite height dimension) and finite differencing. For the solution, the following space and material property dependent discretized diffusion equation is used.

$$
\underline{A} \cdot \underline{\phi}-\left(\frac{v \Sigma_{f}}{k}\right) \cdot \underline{\phi}=\underline{0}
$$

The discretized form of this equation is:

$$
-\frac{D}{\Delta^{2}}\left(\phi_{r+1}\left(\frac{2 r+1}{2 r}\right)-2 \phi_{r}+\phi_{r-1}\left(\frac{2 r-1}{2 r}\right)\right)+\left(\Sigma_{a, r}-\frac{1}{k} v \Sigma_{f, r}\right) \phi_{r}=0
$$

Here, the subscript $r$ indexes to the discrete radial cells in the finite differenced geometry (indexed over 1 to $R$, where $R$ is the total number of cells), $\Delta$ is the cell radial thickness, $D$ is the diffusion coefficient, $\Sigma_{\mathrm{f}, \mathrm{r}}$ is the macroscopic fission cross section of cell $r, \Sigma_{\mathrm{a}, \mathrm{r}}$ is the macroscopic absorption cross section of cell $r$, and $\phi_{\mathrm{r}}$ is the flux on cell $r$. The multiplication factor, $\mathrm{k}$, must also be determined. The multiplication factor is determined using a ratio of the neutron production to the neutron destruction rates for each region, weighted by each regions flux. The diffusion coefficient $D$ is treated as independent of fluence and determined from the transport cross-section $\Sigma_{\text {tr }}$. The diffusion coefficient is treated as independent of fluence and determined from the transport cross-section $\Sigma$ tr. While one group scattering cross sections show far less variation across actinide nuclides than do capture or fission cross sections, an improved approximation of the diffusion coefficient can be obtained using the burnup dependent libraries that will be implemented in the future. Currently the value for the diffusion coefficient can be provided by the user.

The absorption and fission cross sections of each region are derived from the fluence based data. The fluence-based neutron balance approach characterizes the fuel neutron production $(P(F))$ and destruction rate $(D(F))$ as a function of fluence $(F)$ in units of $[\mathrm{n} / \mathrm{s} / \mathrm{unit}$ flux $/ \mathrm{kgIHM}]$. The production $\left(P^{(n)}\right)$ and destruction $\left(D^{(n)}\right)$ rates of region $n$ are found for each batch at its fluence $F^{(n)}$.

$$
\begin{aligned}
& P^{(n)}=P\left(F^{(n)}\right) \\
& D^{(n)}=D\left(F^{(n)}\right)
\end{aligned}
$$

The production and destruction cross sections $v \Sigma^{(n)}$ and $\Sigma^{(n)}$ are calculated from $P^{(n)}$ and $D^{(n)}$.

$$
\begin{aligned}
v \cdot \Sigma_{f}^{(n)}\left[\frac{1}{\mathrm{~cm}}\right] & =P^{(n)}\left[\frac{\mathrm{n}}{s \cdot k g \cdot \phi}\right] \cdot \rho^{(n)}\left[\frac{\mathrm{g}}{\mathrm{cm}^{3}}\right] \\
\Sigma_{a}^{(n)}\left[\frac{1}{\mathrm{~cm}}\right] & =D^{(n)}\left[\frac{\mathrm{n}}{\mathrm{s} \cdot \mathrm{kg} \cdot \phi}\right] \cdot \rho^{(n)}\left[\frac{\mathrm{g}}{\mathrm{cm}^{3}}\right]
\end{aligned}
$$

Here $\rho^{(n)}$ is the average mass density of all the components in region $n$. 
Once the flux vector $\phi_{r}$ is found, the non-normalized average flux over each region $\left(\phi^{(n)}\right)$ is determined by averaging the flux of each cell within the region with the cross sectional area of the cell as its weight:

$$
\phi^{(n)}=\frac{1}{A^{(n)}} \sum_{r: \text { region } n} \phi_{r} \cdot A_{r}
$$

Here $A^{(n)}$ is the area of region $n$, and $A_{r}$ is the radial area of cell $r$.

The normalized fluxes $\left(r^{(n)}\right)$ are determined by dividing the un-normalized average flux values by their maximum.

$$
r^{(n)}=\frac{\phi^{(n)}}{\max \left(\phi^{(1)}, \phi^{(2)}, \ldots, \phi^{(\mathrm{N})}\right)}
$$

These relative fluxes are scaled up in the discharge fluence determination methodology to maintain the reactor power for a given time-step. This scaling is accomplished using the burnup per unit fluence data contained in the libraries. The magnitude of the flux is adjusted so that the burnup per unit time, and hence the reactor power, match the specified target.

Compositions and cross sections change with fluence, which in turn affects the relative flux. Therefore the spatial flux calculation is repeated multiple times during a burnup cycle. The appropriate frequency of recalculation depends on the extent of transmutation-driven spatial redistribution of the flux, which varies by reactor and fuel type.

Even though the spatial methodology can be used to calculate a nonleakage probability, this calculation would not consider leakage in the axial dimension, nor is the spatial approach suitable for accurate treatment of complex radial reflector geometries or explicit modeling of pin-cell level features. Therefore, as was the case with the equal power sharing methodology, the nonleakage probability is kept as a calibration factor to account for reactor-specific neutron leakage rates. The multiplication factor will still be calculated from the definition of $\mathrm{k}$ as the ratio of the core-wide neutron production and loss rates, rather than from the diffusion eigenvalue calculation. The calibration is carried out using benchmark results and used to match a specified outcome of one reference case, typically the steady state discharge burnup achieved for a given fresh fuel composition. 


\section{Results}

\subsection{SPATIAL FLUX VALIDATION USING MCNP}

This section employs coupled neutron transport-burnup calculations to validate and benchmark the method for approximating the inter-region flux distribution and power sharing presented in the previous section. The high-fidelity transport calculations are useful for quantifying the error associated with the simplified approach. To compare equivalent simplified depictions of reactor geometries, the transport calculations were also applied to a simple geometry consisting of homogenized, concentric annular regions.

To that end, the spatial flux profile of a 3 batch LWR core was calculated using MCNP and the spatial method of Bright-lite. The MCNP model of the geometry is shown in Figure 4, where the three inner regions are homogenized fuel batches (each batch is divided into subsections of the same material to resolve the flux spectrum) and the outermost region (blue) is a water moderator. The geometry of the reactor core, moderator ratio, and other parameters were taken from the 3-batch $33 \mathrm{MWd} / \mathrm{kg}$ reactor from [6]. The diffusion coefficients from [7] were used to determine the transport cross-section inputs for Bright-lite. The fuel enrichments of 1.8, 2.4, and $2.66 \%$ were used in both simulators. The fuel region radius of $152.3[\mathrm{~cm}]$ and a moderator outer radius (measured from the center) of $252.3[\mathrm{~cm}]$ was used.

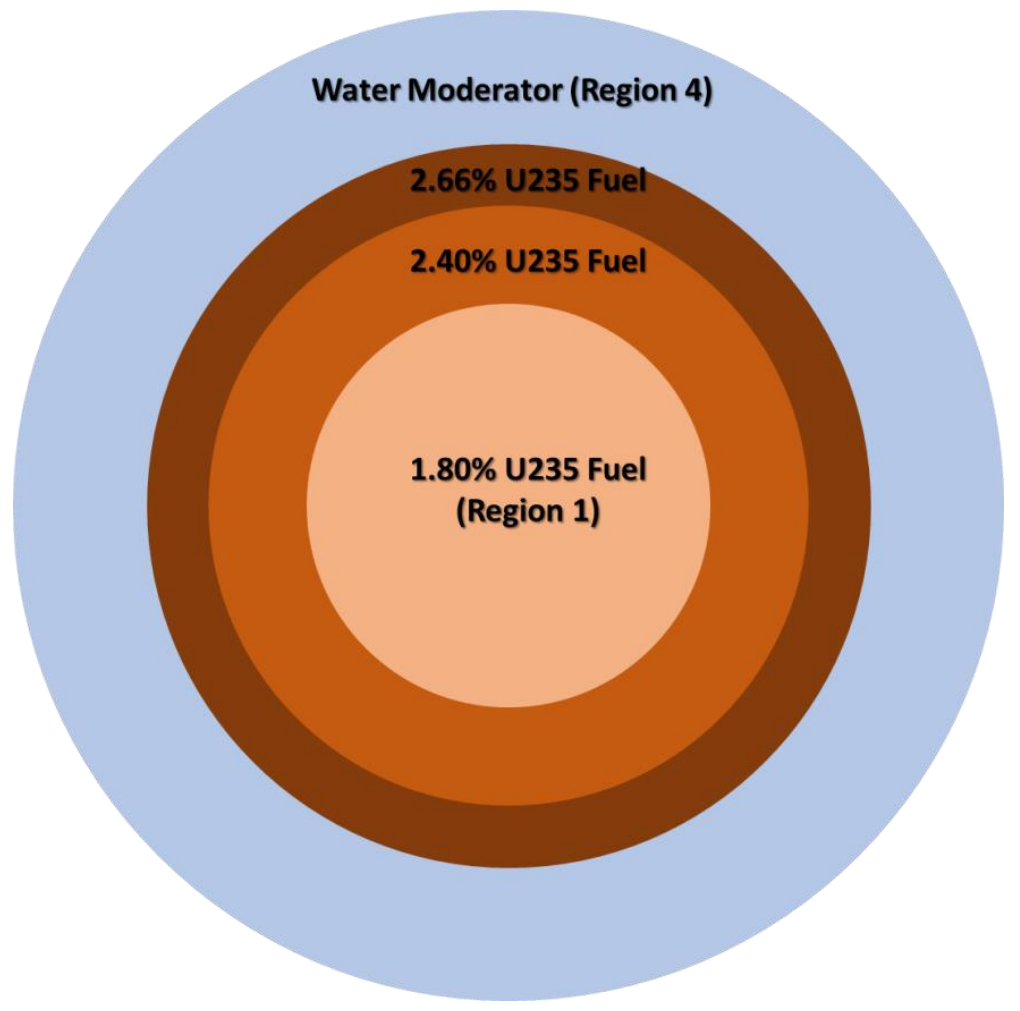

Figure 4 - Geometry of MCNP model. 
Figure 5 shows the flux profiles obtained from Bright-lite and MCNP with the regions occupied by each batch indicated on the $x$-axis. Flux curves were normalized by dividing the data with the maximum flux. The secondary $y$-axis (right side) is used for the relative errors.

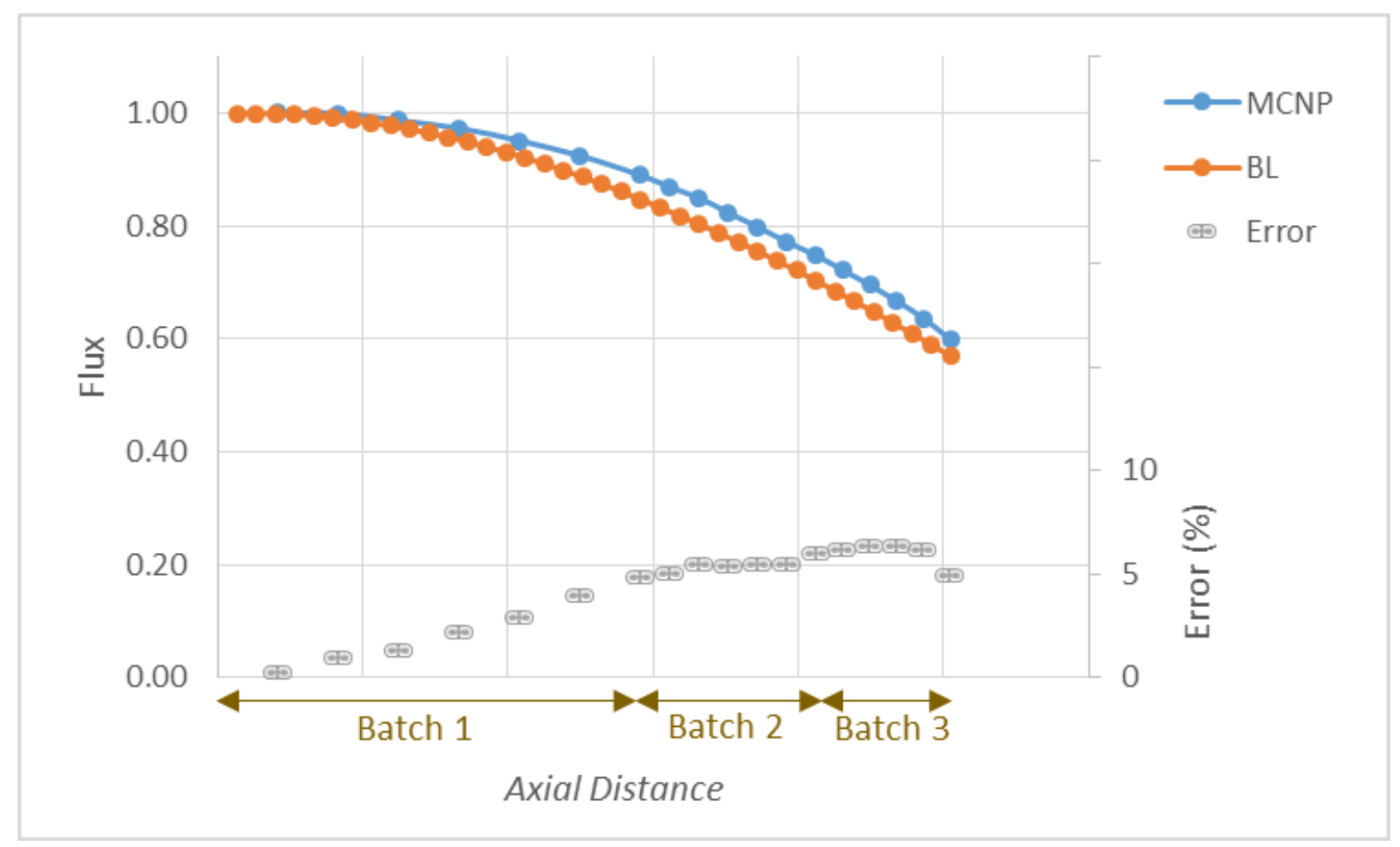

Figure 5 - Normalized flux comparison from spatial method and MCNP.

As expected, the flux distribution is relatively flat in this well-reflected case. Bright-lite shows a steeper decrease compared to MCNP, indicating that the Bright-lite transport calculation predicts somewhat greater neutron leakage and a higher mean free path inside the reactor than does MCNP. Nevertheless the figure demonstrates acceptable agreement between the two results with relative errors limited to less than $6 \%$. 


\subsection{Spatial Method Flux Comparison For Startup Transients In An LWR}

This section presents cases that illustrate the sensitivity of the batch-averaged fluxes to the equal power share and spatial flux approaches. Reactor startup cycles for three cases are presented, each with different degrees of staggering of batch-level enrichments. A subsequent section will compare both startup and equilibrium cycle burnup and material balance results against published values. The MCNP input deck from section 4.1 was modified for this analysis, changing the batch enrichments as necessary.

Table 1 gives the input enrichments and flux results for all three cases. In this study, batches were placed with lowest to highest enrichment proceeding outward, with the active core surrounded by the water region. The fuel and moderator transport cross sections as well as fuel geometry parameters used in the spatial method were taken from [8]. The flux values presented are for the fresh core configuration, the initial Bright-lite flux calculation before any fuel is burned. These relative fluxes evolve as the burnup cycle progresses, but only their initial values are tabulated and compared against the fresh-core MCNP analysis. The table entries compare the area-averaged normalized fluxes in each radial region as calculated by MCNP with the values arrived at by the equal power sharing and spatial approximations.

Table 1 - Summary of staggered batch enrichments and corresponding normalized fluxes.

\begin{tabular}{|c|c|c|c|c|c|}
\hline Batch & 1 & 2 & Error & 3 & Error \\
\hline Enrichment & $4 \%$ & \multicolumn{2}{|c|}{$4 \%$} & \multicolumn{2}{|c|}{$4 \%$} \\
\hline MCNP Flux & 1.000 & 0.848 & & 0.697 & \\
\hline Equal Power Flux & 1.000 & 1.000 & $17.9 \%$ & 1.000 & $43.5 \%$ \\
\hline Spatial Flux & 1.000 & 0.821 & $3.2 \%$ & 0.665 & $4.6 \%$ \\
\hline Enrichment & $1 \%$ & \multicolumn{2}{|c|}{$3 \%$} & \multicolumn{2}{|c|}{$5 \%$} \\
\hline MCNP Flux & 1.000 & 0.895 & & 0.755 & \\
\hline Equal Power Flux & 1.000 & 0.494 & $44.8 \%$ & 0.323 & $57.2 \%$ \\
\hline Spatial Flux & 1.000 & 0.922 & $3.1 \%$ & 0.793 & $5.0 \%$ \\
\hline Enrichment & $1.80 \%$ & \multicolumn{2}{|c|}{$2.20 \%$} & \multicolumn{2}{|c|}{$2.66 \%$} \\
\hline MCNP Flux & 1.000 & 0.856 & & 0.705 & \\
\hline Equal Power Flux & 1.000 & 0.874 & $2.1 \%$ & 0.764 & $8.4 \%$ \\
\hline Spatial Flux & 1.000 & 0.844 & $1.5 \%$ & 0.694 & $1.5 \%$ \\
\hline
\end{tabular}

The first case uses the same enrichment for all three batches. As expected, the equal power sharing approach yields the physically unrealistic result of equal fluxes within each batch. The simple diffusion approximation of the spatial method agrees well with the MCNP calculation, and will allow the effects of unequal power sharing on cycle length, burnup, and discharge isotopics to be captured.

The next example has a steep range for fuel enrichments, from 1 to $5 \%$. The spatial method and MCNP results yield a flattened flux profile for the core, whereas the equal power sharing assumption 
forces a steep and non-physical flux profile due to the high difference in enrichments. The final example represents the most realistic case, with fuel enrichments increasing from 1.8 to $2.66 \%$. Once again, these relative fluxes apply to fresh fuel of the given compositions. It can be observed that the MCNP, equal power, and spatial flux approaches yield similar relative fluxes. This is to be expected as the equal power sharing approach is most applicable to cases where batch enrichments are staggered such that the power distribution is made as nearly uniform as possible. However, even for this case the flux values from the spatial method more closely match the results of MCNP. 


\subsection{REACTOR LIFETIME BURNUP AND ISOTOPICS COMPARISON}

This section examines the burnup and isotopics outputs of Bright-lite operated under the equal power sharing and spatial flux methods. The parameters for this case are taken from The Nuclear Energy Agency's The Economics of The Nuclear Fuel Cycle (EFC) study [6], which uses COSI to generate results. The $33 \mathrm{MWd} / \mathrm{kg}$ LWR reactor is selected from this study. The input fuel compositions for this reactor are given in Table 2. The spatial method inputs described in section 4.1 (excluding fuel enrichments) were used in this case. Cycle length was determined by core multiplication dropping below unity in the absence of control absorbers.

Table 2 - Input fuel enrichments used for Section 3.3 Comparison Study

\begin{tabular}{|cc|}
\hline Batch & Enrichment [\%] \\
$\mathbf{1}$ & 1.500 \\
$\mathbf{2}$ & 2.400 \\
$\mathbf{3}$ & 2.950 \\
\hline $\mathrm{n}>\mathbf{3}$ & 3.100 \\
\hline
\end{tabular}

The LWR reactor in this study operates with 3 batches, with a steady state U-235 enrichment of 3.1\%. The Bright-lite's spatial analysis was initialized with the $1.5 \%$ enriched batch 1 at the center and batches 2 and 3 were located in successive annular rings. A water moderator/reflector fills the outermost ring. Shuffling is simulated by moving older batches inward during refueling and placing fresh fuel in the outermost fuel ring. The fuel and moderator transport cross sections, as well as fuel geometry parameters used in the spatial method were taken from [8].

The discharge burnups of the first five batches and the final two batches discharged at reactor decommissioning are given in Figure 6. Note that the nonleakage probabilities were used as calibration factors, causing the equilibrium batch burnups to be equal for all three sets of results. 


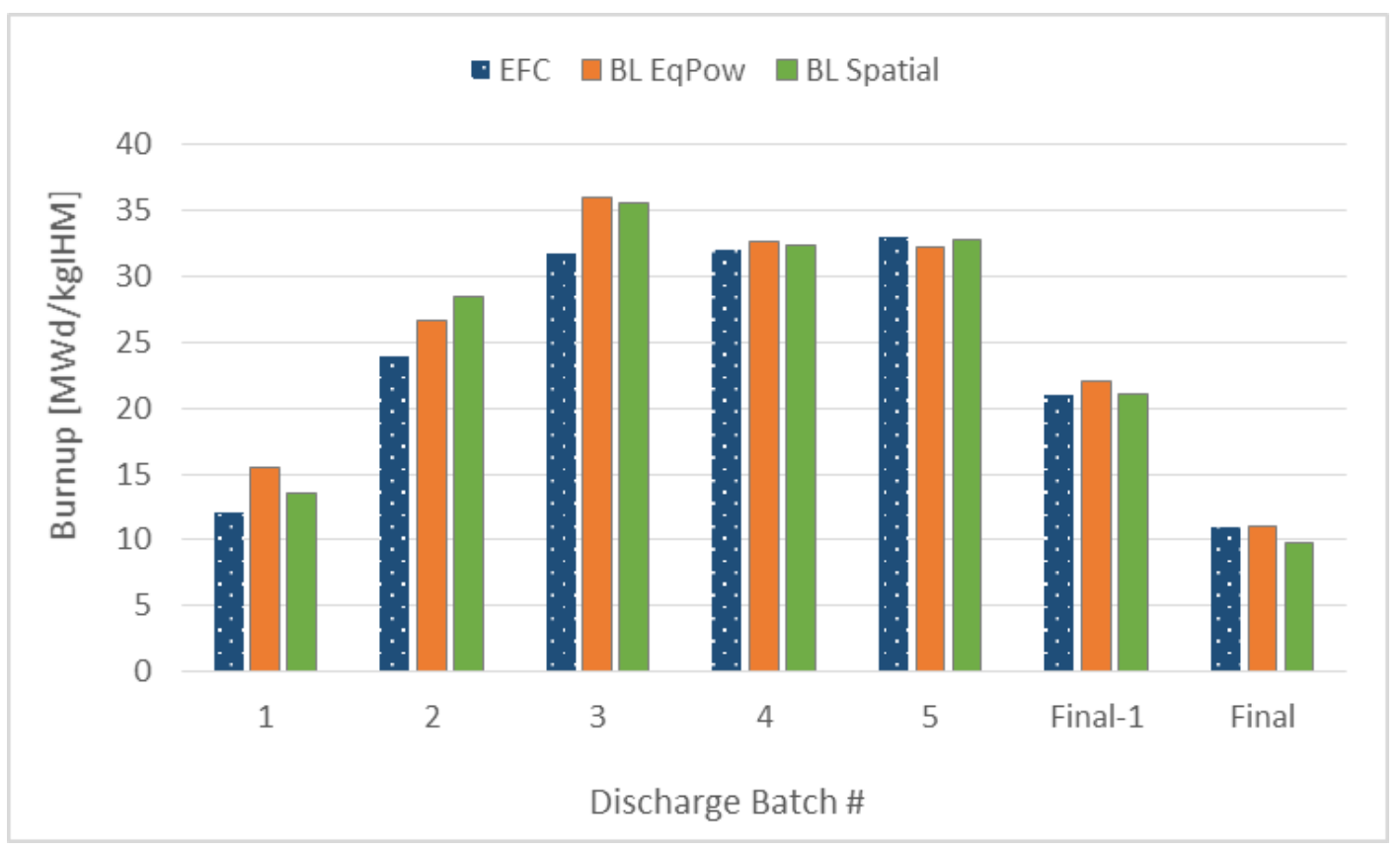

Figure 6 - Lifetime discharge burnup comparison of Bright-lite's two methods.

Both approaches are seen to yield very reasonable predictions of batch discharge burnups for this case where the initial enrichment staggering and homogenous fuel are such that the equal power sharing assumption is quite reasonable (see previous section). The equal power sharing assumption provides results closer to the EFC study for the second and final batches. However, the average error (averaged over all 7 discharge burnups shown in the figure) for the equal power assumption is $9.00 \%$, compared to an error of $8.20 \%$ for the spatial method.

Next, the U-235 content in discharge batches is shown in Figure 7. The average error for the spatial flux method was $9.58 \%$, compared to the $11.86 \%$ error of the equal power sharing method. 


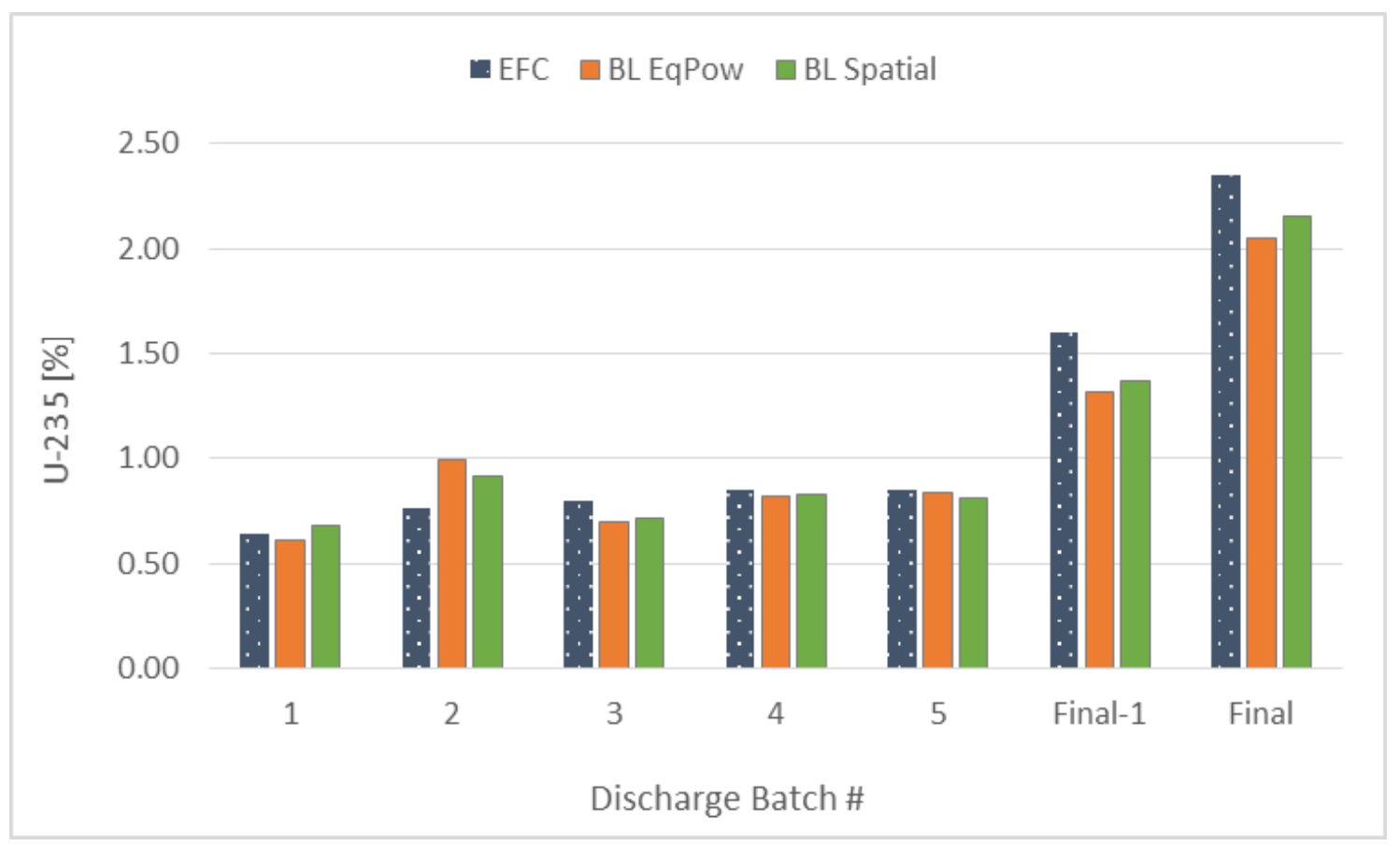

Figure 7 - Lifetime discharge U-235 concentration comparison of Bright-lite's two methods.

Figure 8 and Figure 9 show the fissile plutonium (Pu-239+ Pu-241) and total plutonium content of discharge batches. It can be observed from these figures that the agreement on discharge isotopics is consistently similar for both methods.

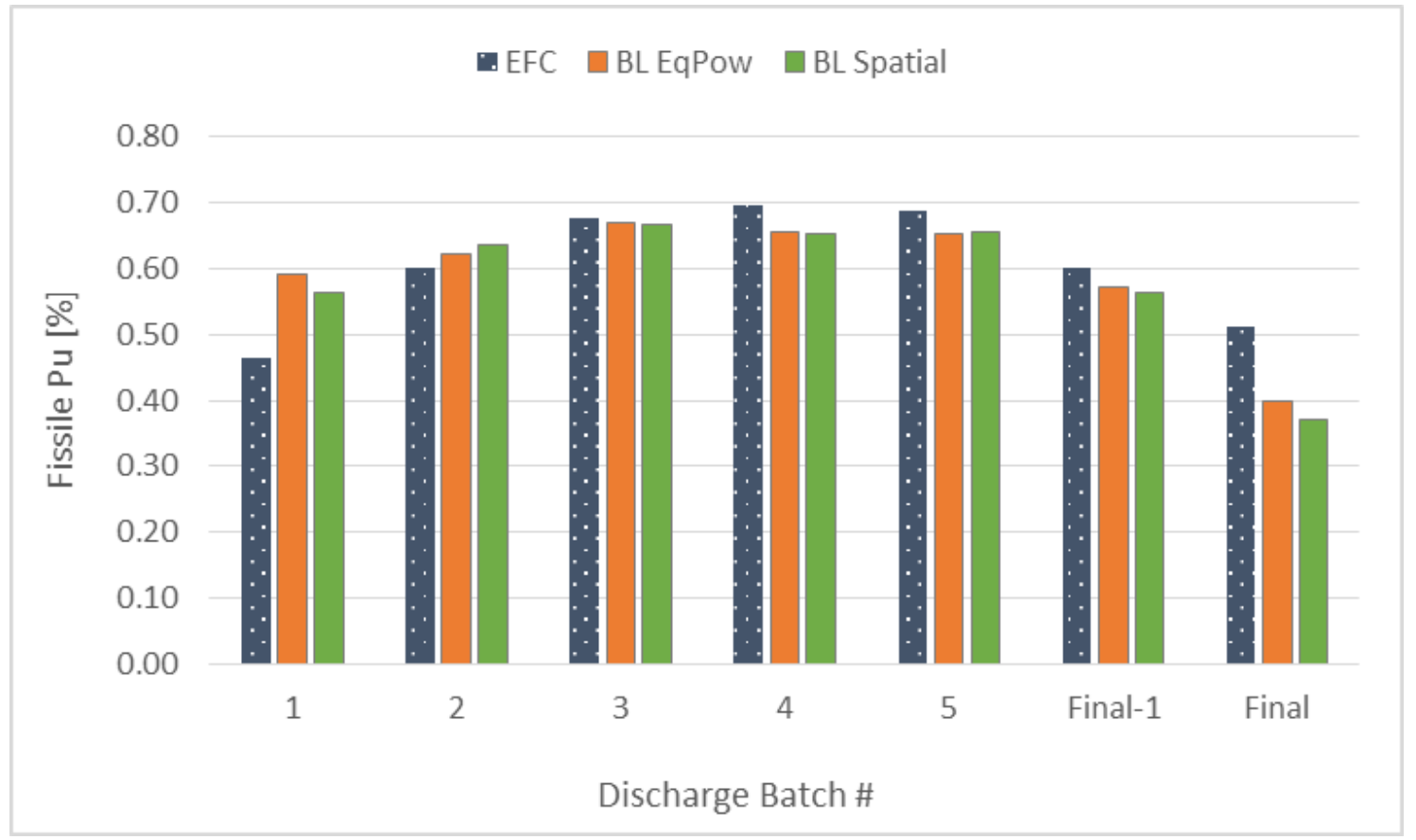

Figure 8 - Lifetime discharge Fissile $\mathrm{Pu}$ concentration comparison of Bright-lite's two methods. 


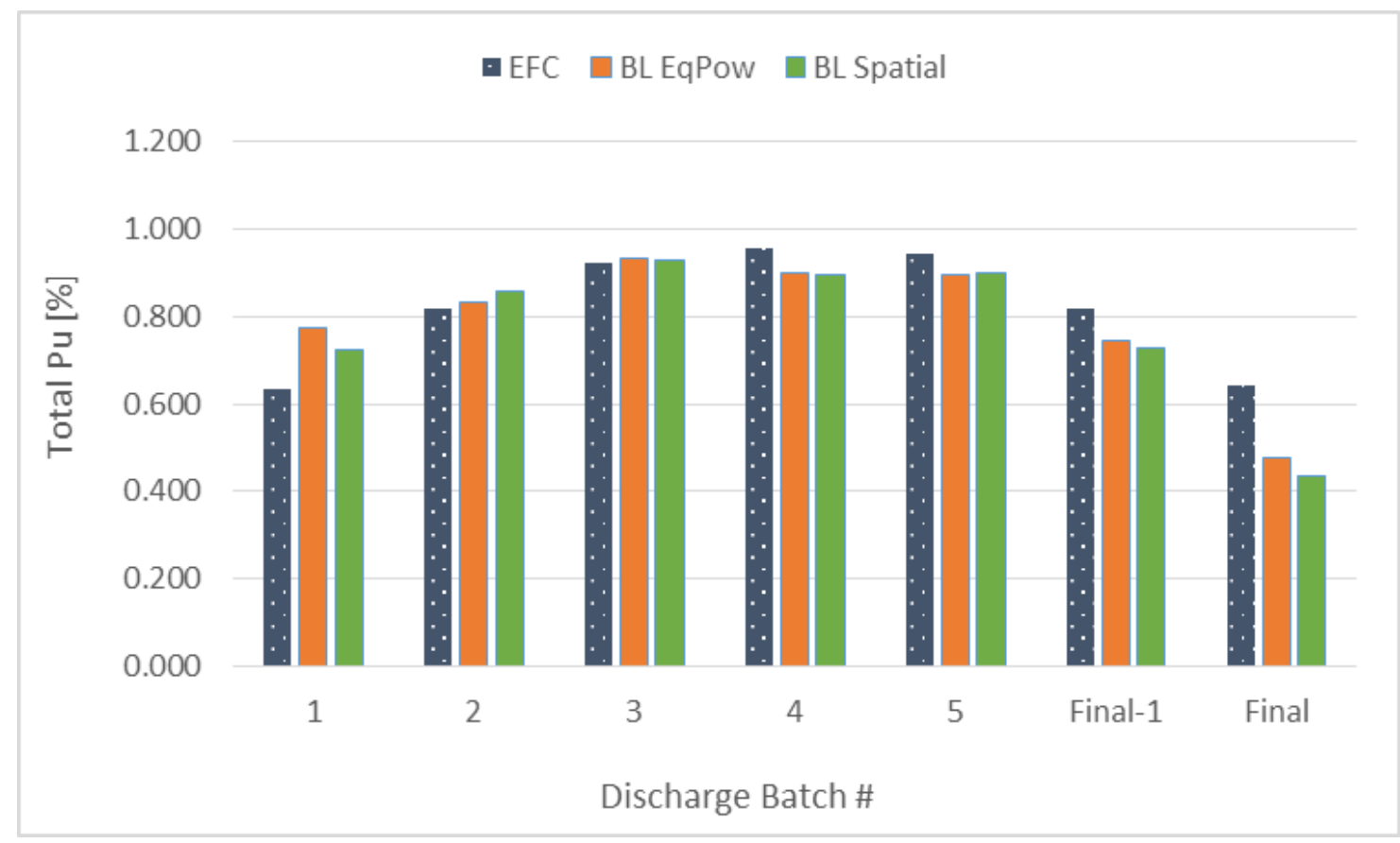

Figure 9 - Lifetime discharge Total Pu concentration comparison of Bright-lite's two methods.

There is little difference between the total $\mathrm{Pu}$ content and $\mathrm{Pu}$ isotopics arrived at by the two methods, and both are in reasonable agreement with the EFC study. This result is not unexpected for this LWR case where the equal power sharing assumption is best suited. 


\subsection{DRIVER-BLANKET REACTOR}

In this section a fast breeder reactor simulation is benchmarked against a case with parameters taken from [9]. The core lattice of the benchmark is given in Figure 10. It can be observed that the reactor has drivers in the central two cylindrical zones of the reactor, surrounded by the blanket and then the reflector. In the Bright-lite implementation a 1-D axial-symmetric model based on this benchmark is used.

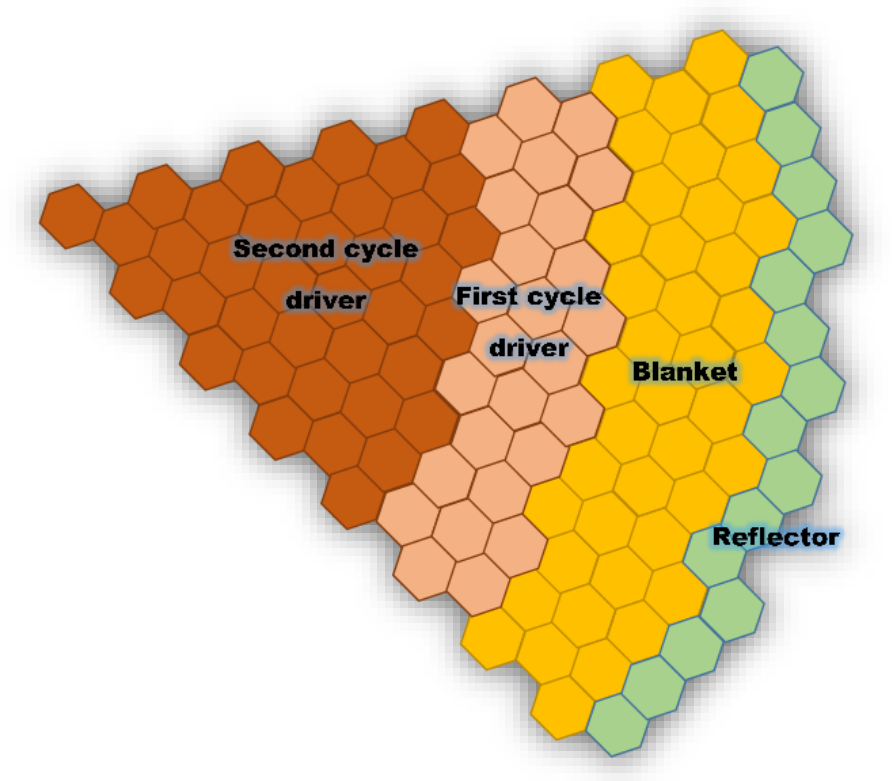

Figure 10 - Driver-blanket core setup from benchmark source.

Important parameters for the case are presented in Table 3. The power and dimensions of the core are given here as well as fuel composition information, all used as inputs for Bright-lite. It can be seen that the innermost region of the core is the second cycle driver, with a lower enrichment than that of the fresh first cycle driver. The drivers are surrounded by the blanket, with over an order of magnitude less fissile material enrichment than the average driver enrichment. Bright-lite takes the compositions of fresh driver and blanket as inputs (Shown in Table 4) and calculates the composition of the second cycle driver as well as the discharge burnups of both driver and blanket. The driver and blanket are sodium cooled, and the majority of the power production comes from the driver. At the end of every cycle the second cycle driver gets discharged and replaced by the first cycle driver, and the blanket gets replaced every five cycles.

Table 3 - Driver-blanket benchmark reactor parameters.

\section{Parameters Used for Bright-lite Inputs}

Power [MWth]

Power [MWe] 


\begin{tabular}{|c|c|}
\hline Core height [mm] & 1016 \\
\hline Driver Radius [mm] & 1320 \\
\hline Axial Blanket Thickness [mm] & 381 \\
\hline Axial Reflector Thickness [mm] & 76.2 \\
\hline Fuel Pin Outer Diameter [mm] & 7.62 \\
\hline First cycle driver fissile nuclide content [\%] & 15.08 \\
\hline Blanket fissile nuclide content [\%] & 1.57 \\
\hline Pu 239-240-241-242 Comp [\%] & $68.0-19.4-10.2-2.4$ \\
\hline Driver fractions (fuel-sodium-structure) & $0.3845-0.3845-0.2157$ \\
\hline Blanket fractions (fuel-sodium-structure) & $0.5613-0.234-0.1653$ \\
\hline Driver / blanket residence time [cycles] & $2 / 5$ \\
\hline Parameters Bright-lite Calculates & \\
\hline Second cycle driver fissile nuclide content [\%] & 10.42 \\
\hline Power Split driver / blanket & $92.6 / 4.3$ \\
\hline Driver BU [MWd/kg] & 56.2 \\
\hline Blanket BU [MWd/kg] & 2.5 \\
\hline
\end{tabular}

The input fuel material compositions are presented in Table 4. These compositions were taken from [9] and used to define the three startup regions (driver-driver-blanket) in Bright-lite. The dimensions of the core for the spatial flux calculation are taken from the given dimensions in Table 3 and Figure 10. The power split between the driver and blanket was calculated by Bright-lite.

Table 4 - Material compositions in atom \% for driver-blanket benchmark.

\begin{tabular}{|c|c|c|}
\hline Material & Driver [atom \%] & Blanket [atom \%] \\
\hline Sodium & $3.85 \mathrm{E}+01$ & $2.34 \mathrm{E}+01$ \\
\hline Structural Materials & $2.16 \mathrm{E}+01$ & $1.65 \mathrm{E}+01$ \\
\hline U-235 & $6.53 \mathrm{E}-02$ & $1.11 \mathrm{E}-01$ \\
\hline U-238 & $3.26 \mathrm{E}+01$ & $5.51 \mathrm{E}+01$ \\
\hline Pu-239 & $3.94 \mathrm{E}+00$ & $5.99 \mathrm{E}-01$ \\
\hline Pu-240 & $1.12 \mathrm{E}+00$ & $1.71 \mathrm{E}-01$ \\
\hline Pu-241 & $5.91 \mathrm{E}-01$ & $8.99 \mathrm{E}-02$ \\
\hline Pu-242 & $1.39 \mathrm{E}-01$ & $2.11 \mathrm{E}-02$ \\
\hline
\end{tabular}

In Bright-lite it was necessary to simulate the startup transient of the reactor in order to reach an equilibrium that could be compared with the published values. Hence at the startup of the Bright-lite reactor the two innermost regions of the core, used for the driver, were composed of the same material. Relative fluxes were calculated making use of the material composition, dimensions, and reactor libraries using the spatial method. In every later reactor cycle new fuel was loaded to the outer 
of the driver regions and the older driver was shifted inside. By matching the equilibrium cycle burnup to the published value, the nonleakage probability calibration factor was selected to be 0.90 . Based on spatial meshing and time step convergence studies a delta of $1.5[\mathrm{~cm}$ ] and a $\Delta \mathrm{t}$ of 15 [days] were selected. Spatial flux calculations were performed at every time-step, and discharge fluence was determined to be achieved when core criticality dropped to unity.

Figure 11 depicts the burnup results of the driver batches over several reloads and compares the result to the benchmark. In the figure, "Cycle 1 Total Burnup" indicates the burnup reached at the end of the first (of two) cycles, and "Discharge Burnup" is the total burnup at the end of two cycles. The arrow in the figure illustrates that the same batch moves in the core during reload. Since the first batch is only present in the core for one cycle, it is only included with the discharge burnups. The steady state discharge burnup of the driver in Bright-lite is determined to be $56.4 \mathrm{MWd} / \mathrm{kglHM}$, compared to the benchmark value of 56.2 .

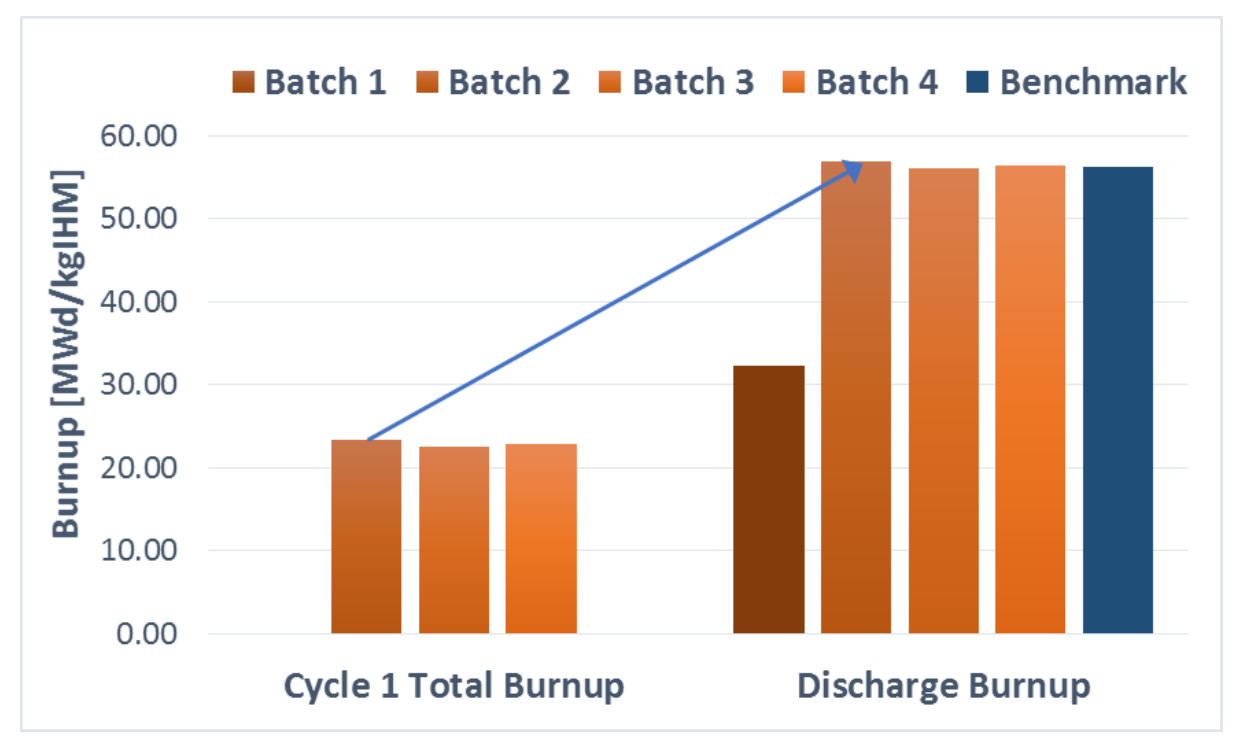

Figure 11 - Driver end of first cycle and discharge total burnups, with benchmark comparison for driver-blanket case.

Figure 12 depicts the burnups of the blanket at the end of each cycle for two batches. Each blanket batch remains in the core for five cycles. Similar to the previous figure, the presented values are total burnups at the given cycle. As expected, the burnup for the blanket is low, with the Bright-lite result being $3.31 \mathrm{MWd} / \mathrm{kglHM}$. This is over the benchmark value of $2.5 \mathrm{MWd} / \mathrm{kglHM}$ with an error approaching $25 \%$. The burnup value is very low and minimally affects overall power production. However, the effect on the mass balance can more pronounced as small deviations in burnup can translate into significant changes in breeding ratio and plutonium production in the blanket. The higher burnup predicted by Bright-lite indicates that the average neutron flux it predicts for the blanket region is too large. This likely arises from the reflector outside the blanket, which is also modeled as having infinite height. The significant underestimation of leakage that results could be addressed by calibrating the reflector thickness to attain the target blanket-to-core flux ratio. 


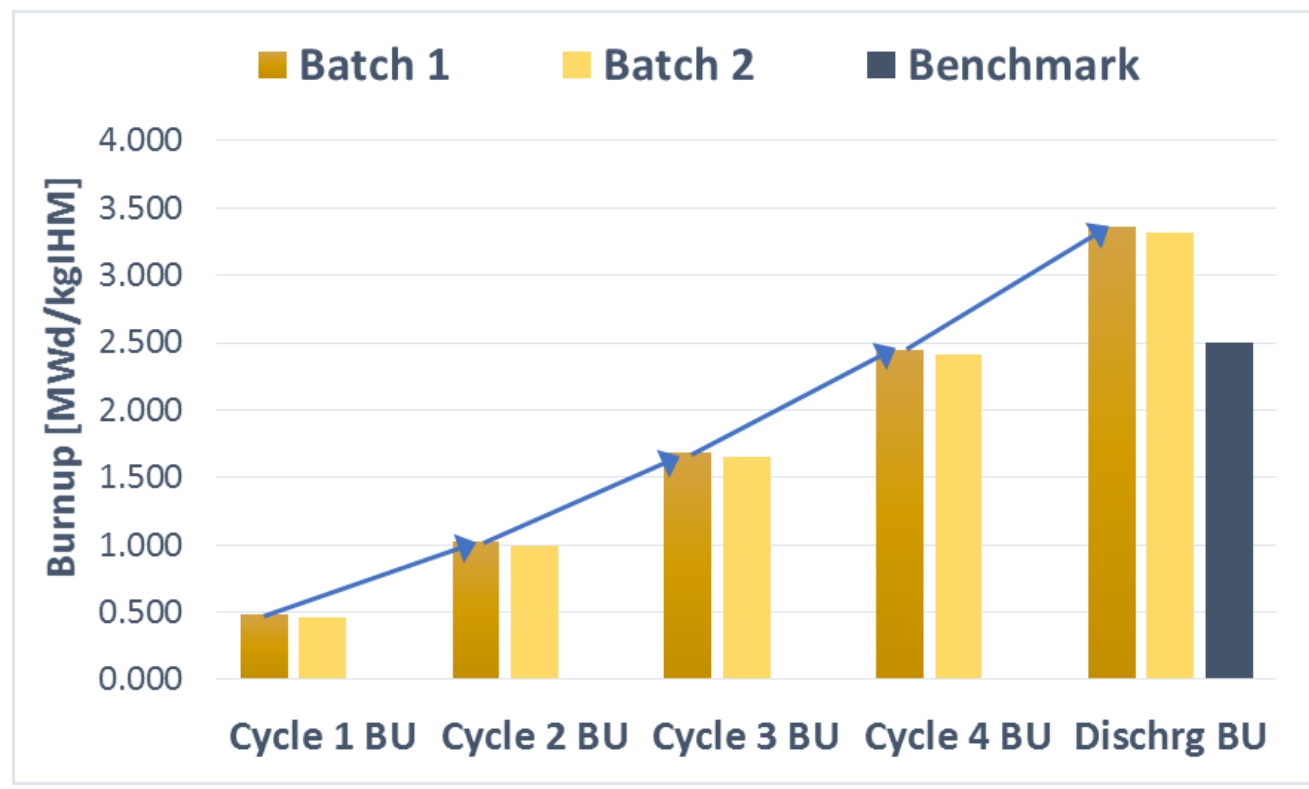

Figure 12 - Blanket burnups and benchmark discharge burnup comparison for driver-blanket benchmark.

The discharge compositions obtained from Bright-lite are given in Table 5. This table shows selected nuclides from the discharge composition of the driver after two full cycles during steady state operation and driver after five full cycles. Note that the benchmark does not provide output isotopics for comparison. However the starting fissile isotope content for the second cycle driver was given as $10.42 \%$ in the benchmark. Bright-lite calculates this value for the steady state batch as $9.492 \%$, an error of less than $10 \%$.

Table 5 - Driver-blanket case driver discharge compositions from Bright-lite.

\begin{tabular}{|c|c|c|}
\cline { 2 - 3 } \multicolumn{1}{c|}{} & $\begin{array}{c}\text { Bright-lite Driver } \\
\text { Output at } \\
\text { Discharge [\%] }\end{array}$ & $\begin{array}{c}\text { Bright-lite Blanket } \\
\text { Output at } \\
\text { Discharge [\%] }\end{array}$ \\
\hline U-235 & $9.52 \mathrm{E}-02$ & $1.66 \mathrm{E}-01$ \\
\hline Pu-239 & $8.75 \mathrm{E}+00$ & $2.67 \mathrm{E}+00$ \\
\hline Pu-240 & $2.34 \mathrm{E}+00$ & $3.38 \mathrm{E}-01$ \\
\hline Pu-241 & $6.38 \mathrm{E}-01$ & $1.37 \mathrm{E}-01$ \\
\hline Pu-242 & $2.87 \mathrm{E}-01$ & $3.98 \mathrm{E}-02$ \\
\hline Am-241 & $7.08 \mathrm{E}-02$ & $4.10 \mathrm{E}-03$ \\
\hline Am-243 & $2.23 \mathrm{E}-02$ & $9.67 \mathrm{E}-04$ \\
\hline
\end{tabular}


This case successfully demonstrates the new capability of the spatial flux method by simulating a driver-blanket core. Accurate output composition results were obtained by the introduction of spatial regions and batch-based fuel reshuffling, with transient composition error under $10 \%$. Introduction of case-specific library databases and cross-sections (which are currently approximate) can further improve these results. 


\subsection{MIXED MOX-UO2 REACTOR}

In this section a PWR loaded with assemblies containing approximately one-third MOX rods in a CORAIL loading scheme is simulated. The case parameters are taken from [10]. This reference investigates various options for plutonium multirecycling in standard PWR's using the transport code APOLLO2 [11]. The chosen case is a steady state calculation; the fresh compositions for both types of fuel are given in Table 6. These values were used as inputs for the steady state calculation in Bright-lite. The MOX rods represent a mixture of natural uranium and plutonium from used fuel.

Table 6 - Assembly rod compositions used in the reference case and Bright-lite.

\begin{tabular}{|l|c|c|}
\cline { 2 - 3 } \multicolumn{1}{c|}{} & MOX Rods (weight \%) & UO2 Rods (weight \%) \\
\hline U-234 & $3.40 \mathrm{E}-03$ & \\
\hline U-235 & $6.54 \mathrm{E}-01$ & $5.30 \mathrm{E}+00$ \\
\hline U-238 & $9.13 \mathrm{E}+01$ & $9.47 \mathrm{E}+01$ \\
\hline Pu-238 & $2.16 \mathrm{E}-01$ & \\
\hline Pu-239 & $4.48 \mathrm{E}+00$ & \\
\hline Pu-240 & $2.07 \mathrm{E}+00$ & \\
\hline Pu-241 & $5.92 \mathrm{E}-01$ & \\
\hline Pu-242 & $5.84 \mathrm{E}-01$ & \\
\hline Am-241 & $5.60 \mathrm{E}-02$ & \\
\hline
\end{tabular}

Additional information about the assemblies used in this study are summarized in Table 7. In the reference each assembly has the $\mathrm{UO}_{2}$ rods at the center, surrounded by the MOX rods.

Table 7 - Assembly information from the reference case.

\begin{tabular}{|l|c|}
\hline $\begin{array}{l}\text { Burnup } \\
\text { [MWd/kglHM] }\end{array}$ & 60 \\
\hline $\begin{array}{l}\text { Power } \\
\text { [MWth] }\end{array}$ & 3800 \\
\hline $\begin{array}{l}\text { Assembly } \\
\text { mass [kg] }\end{array}$ & 535 \\
\hline $\begin{array}{l}\text { Fuel } \\
\text { Management }\end{array}$ & $\begin{array}{l}4 \\
\text { batches/core }\end{array}$ \\
\hline MOX Rods & 84 \\
\hline UO2 Rods & 180 \\
\hline
\end{tabular}

Each assembly was modeled using two burnup and transmutation libraries, one for each rod type. There was insufficient data in the reference to prepare one group cross sections directly applicable to this fuel loading, so libraries for full-assembly PWR MOX and UOX of equivalent burnup were used. Since Bright-lite simulates reactors from startup, to model this case the CORAIL reactor was continuously 
refueled until steady-state was reached. This required 8 refueling cycles. The Bright-lite nonleakage probability was used as a calibration tool to attain the target steady state discharge burnup of 60 $\mathrm{MWd} / \mathrm{kg}$. From there, cycle length was determined based on core reactivity constraints.

The spatial calculation was carried out for four radial fuel regions, each corresponding to a smeared $\mathrm{UO}_{2} / \mathrm{MOX}$ fuel batch. An additional water moderator region was used as the outermost spatial region. For the spatial calculation a core radius of $168 \mathrm{~cm}$ and a moderator axial thickness of $30 \mathrm{~cm}$ was selected. At each fuel reloading the innermost region was removed and the other three fuel regions were shifted inward. Mass weighted average fission and absorption cross sections were used for each fuel region in the spatial flux calculation. The transmutation calculations were carried out with separate libraries for $\mathrm{MOX}$ and $\mathrm{UO}_{2}$.

Table 8 presents the discharge composition from the reference and Bright-lite for a steady state assembly. These results are mass-weighted totals of both types of fuel rods since the reference only provides aggregated mass balance data for a full assembly. It can be observed that the errors are in the order of $10 \%$ with the exception of Pu-242, which has an error of $33.3 \%$. The high mass of Pu-242 can be due to discrepancies in the relative cross sections of plutonium.

Table 8 - Steady state discharge composition comparison for the mixed assembly.

\begin{tabular}{|l|c|c|r|}
\hline Isotope & Reference & Bright-lite & Error (\%) \\
\hline U-235 & $8.08 \mathrm{E}-03$ & $7.18 \mathrm{E}-03$ & 11.2 \\
\hline U-236 & $5.08 \mathrm{E}-03$ & $5.34 \mathrm{E}-03$ & 5.2 \\
\hline U-238 & $9.60 \mathrm{E}-01$ & $9.59 \mathrm{E}-01$ & 0.1 \\
\hline Pu-238 & $1.04 \mathrm{E}-03$ & $9.36 \mathrm{E}-04$ & 9.6 \\
\hline Pu-239 & $1.02 \mathrm{E}-02$ & $1.10 \mathrm{E}-02$ & 8.2 \\
\hline Pu-240 & $7.94 \mathrm{E}-03$ & $7.31 \mathrm{E}-03$ & 7.9 \\
\hline Pu-241 & $4.48 \mathrm{E}-03$ & $4.83 \mathrm{E}-03$ & 7.7 \\
\hline Pu-242 & $3.18 \mathrm{E}-03$ & $4.24 \mathrm{E}-03$ & 33.3 \\
\hline
\end{tabular}

This approach for the reactor types considered has been shown to give errors in the material balance of generally below $10-20 \%$, not out of line with differences in end of equilibrium cycle balances for other fuel cycle simulators, many of which couple directly to transport codes. A benchmark study with 5 computer codes evaluating UOX and MOX reactors found nuclide material balance differences from the mean of up to 15\% [12]. A similar report conducted by OECD/NEA which compares results from 13 institutes in 7 countries found differences from the mean up to $20 \%$ for several nuclides among participants' results [13]. 


\section{Conclusion}

The fluence based neutron balance approach is used to calculate input and output compositions of fuel in nuclear fuel cycle simulators. However, the method cannot be used to simulate complex cores such as driver-blanket or UOX-MOX mixed reactors. This limits the applicability and use of Bright-lite, which uses the method, as many future reactor technologies cannot be simulated. The paper demonstrates that Bright-lite's equal power sharing method can be generalized to an approach that handles various reactor types where equal power sharing assumption falls short while still retaining its ability to quickly calculate material balances. This method is used to estimate the flux distribution of a core in a given state. The calculated time-dependent fluxes in each macroscopic region is used to correctly advance the fluence of macro regions, calculate fission rates and power densities, and evaluate the overall neutron balance of the reactor. The capability of the spatial flux method to simulate heterogeneous cores has been demonstrated in the results. The material balance differences are generally under $20 \%$, in line with differences presented in benchmark studies comparing multiple codes coupled with transport software.

In order to mitigate the impact of the spatial method on simulation runtime, it uses a relatively crude, macroscopic estimate of the flux profile. Bright-lite is a quick execution software and cannot achieve the accuracy of higher fidelity calculations. For example, in some cases reactors may employ a complex core lattice that cannot be acceptably reduced to a concentric cylinder geometry. For such cases, the spatial method can only be used in an approximate sense, after intelligent grouping of core materials to a representative concentric cylinder geometry. In addition, the spatial method relies upon diffusion parameters such as transport cross-sections, which are approximate in the sense that they are treated as calibration parameters. For certain reactors, for example fast-spectrum systems with high leakage due to high mean free paths, the well-known limitations of diffusion theory also apply.

There is a need to generalize the methodology to account for burnup dependence in the precalculated and parameterized burnup and transmutation libraries. Libraries are generated as a function of fluence for a unit mass of irradiated material, so the chief obstacle to incorporating burnup dependence is that the fluence-burnup relationship is not a priori known. Therefore, this complicates efforts to convolve an appropriately burnup-varying flux spectrum with the nuclear data to arrive at appropriately burnup-dependent libraries. A path forward that is expected to give reasonable results is to precompute a representative burnup-varying spectrum and burnup-fluence relationship for each reactor type considered by Bright-lite. Those items will enable Bright-lite to implement fluencedependent cross sections in place of the constant values used at present.

Possible future work includes intuitive and powerful core geometry and arrangement inputs for reactors using the spatial flux method. In addition, the determination of transport cross-sections can be significantly improved in the future. Finally, rigorous benchmarking and standardization of typical commercial reactors and their input parameters would make the code more accessible and easy to use for many users. 


\section{Acknowledgements}

The authors wish to acknowledge the support of the US Department of Energy Office of Nuclear Energy under Nuclear Energy University Programs Grant number 12-4065." 


\section{Bibliography}

[1] R. Flanagan, E. Schneider and C. Bagdatlioglu, "Fuel Composition Calculation Techniques of Nuclear Fuel Cycle Simulators," in PHYSOR, Kyoto, Japan, 2014.

[2] S. Yee, Nuclear Fuel Cycle Modeling Approaches for Recycling and Transmutation of Spent Nuclear Fuel (Thesis), Ohio State University, 2008.

[3] L. Boucher and J.-P. Grouiller, COSI: a simulation software for a pool of reactors and fuel cycle plants, China: Atomic Energy Press, 2005. 2006.

[5] M. Bell, "ORIGEN: the ORNL isotope generation and depletion code," Oak Ridge National Lab, Tenn. (USA), 1973.

[6] "The Economics of The Nuclear Fuel Cycle," Nuclear Energy Agency and OECD, 1994.

[7] K. S. Smith, "Assembly Homogenization Techniques for Light Water Reactor Analysis," Progress in Nuclear Energy, vol. 17, pp. 303-335, 1986.

B. Lamarsh, Introductin to Nuclear Engineering, New Jersey: Prentice-Hall, 2001.

W. P. Bathold and J. C. Beitel, "Perfomance Charateristics of Homogeneous Versus Heterogenous Liquid-Metal Fast Breeder Reactors," Nuclear Technology, vol. 44.

G. Youinou and A. Vasile, "Plutonium Multirecycling in Standard PWRs Loaded with Evolutionary Fuels," Nuclear Science and Engineering, no. 151, pp. 25-45, 2005.

R. Sanchez, I. Zmijarevic, M. Coste, E. Masielo, S. Santandrea, E. Martinolli, L. Villate, N. Schwartz and N. Guler, "APOLLO2 YEAR 2010," 2010.

Nuclear Energy Agency, "Benchmark Study on Nuclear Fuel Cycle Transition Scenarios Analysis Codes," Nuclear Science, 2012.

Y. N. K. S. Hiroshi OKUNO, "OECD/NEA Burnup Credit Criticality Benchmarks Phase IIIB: Burnup Calculations of BWR Fuel Assemblies for Storage and Transport," Japan Atomic Energy Research Institute, 2002. 